Cahiers $d u$ MONDE RUSSE

\section{Cahiers du monde russe}

Russie - Empire russe - Union soviétique et États indépendants

$52 / 4 \mid 2011$

Varia

\title{
Karen Petrone, The Great War in the Russian Memory
}

Alexandre Sumpf

\section{(2) OpenEdition}

Journals

Édition électronique

URL : http://journals.openedition.org/monderusse/7506

DOI : $10.4000 /$ monderusse. 7506

ISSN : $1777-5388$

Éditeur

Éditions de l'EHESS

\section{Édition imprimée}

Date de publication : 20 décembre 2011

Pagination : 731-734

ISBN : 978-2-7132-2353-2

ISSN : $1252-6576$

Référence électronique

Alexandre Sumpf, "Karen Petrone, The Great War in the Russian Memory », Cahiers du monde russe [En ligne], 52/4 | 2011, mis en ligne le 30 novembre 2012, Consulté le 25 septembre 2020. URL : http:// journals.openedition.org/monderusse/7506; DOI : https://doi.org/10.4000/monderusse.7506

Ce document a été généré automatiquement le 25 septembre 2020.

(c) École des hautes études en sciences sociales 


\title{
Karen Petrone, The Great War in the Russian Memory
}

\author{
Alexandre Sumpf
}

\section{RÉFÉRENCE}

Karen PETRONE, The Great War in the Russian Memory. Bloomington : Indiana

University Press, 2011, Xv +385 p.

1 Il est peu de dire que cet ouvrage vient combler un manque : en dépit d'un intérêt scientifique croissant pour la Première Guerre mondiale en Russie, la somme des travaux reste dérisoire par rapport à l'attention exacerbée dont bénéficie ce conflit sur le front français. Le premier mérite de l'auteur est de démontrer que cette ignorance généralisée ne se justifie ni par la pauvreté événementielle, ni par l'inintérêt des productions culturelles ayant trait à cette épreuve nationale. Sof'ja Fedorčenko, Jakov Okunev, Lev Vojtolovskij, Kirill Levin ou Aleksandr Pirejko, sans oublier Isaak Babel', Il 'ja Erenburg et Mihail Šolohov, ont été en Russie les Barbusse, les Remarque de l'entredeux-guerres. En exhumant une très riche littérature, Karen Petrone, spécialiste des rituels soviétiques, invalide donc l'idée d'une guerre oubliée ou bien plongée dans des oubliettes politiques par le régime bolchevik.

2 À juste titre, l'auteur appuie son argumentation autant sur les interventions étatiques que sur les vecteurs privés de la mémoire du conflit, et insiste sur les continuités plutôt que sur les ruptures du « discours soviétique sur la Première Guerre mondiale ». La Russie partage avec l'ensemble des sociétés belligérantes une perception du conflit marquée par la religion (la guerre sainte), l'héroïsme masculin, la violence et son ambiguïté morale, le patriotisme. Mais elle se distingue par une série de critiques plus virulentes qu'ailleurs: l'impérialisme, un entraînement militaire aussi brutal qu'inefficace, les mauvais traitements infligés par les officiers à leurs soldats, les désillusions rapides de la population après une période courte d'enthousiasme mesuré. 
3 Après le chapitre introductif, le lecteur aborde successivement la spiritualité et la définition des genres masculins et féminins, tous deux mis à l'épreuve par la guerre (2-3), la violence et la conscience du combattant (4), et l'identité russe en miroir de la figure de l'ennemi (5). L'ouvrage adopte donc un plan thématique, puis déplace intelligemment son propos vers une échelle moins globale avec des études de cas (6), ou le situe dans le temps long du $\mathrm{xx}^{\mathrm{e}}$ siècle soviétique et postsoviétique (7). Si Petrone fait référence au conflit contre le Japon en 1904-1905, l'impact culturel et savant sur la société russe de la première guerre moderne qu'ait connu la Russie aurait mérité à notre sens un développement plus conséquent - allant notamment au-delà de la problématique (bien réelle) de la défaite.

4 L'imagerie religieuse associée au culte de la famille impériale, le mysticisme et la superstition du peuple russe attestés à longueur de documents, les prêches des ecclésiastiques de toutes les religions entretiennent une atmosphère religieuse teintant fortement l'expérience russe de la guerre. Ces références religieuses ne disparaissent ni du fait de la révolution, ni sous les coups de boutoir réguliers (1922-1923, 1929-1931, 1937) du régime, comme en témoignent lettres de soldats et ouvrages convoqués. Mieux, le religieux offre un cadre au deuil des familles plus propice que la «mémoire éternelle ", presque anonyme, proposée par le discours soviétique sur la mort au combat. Mais hors une intéressante analyse des funérailles du général Brusilov en 1926, mêlant tradition orthodoxe et innovations socialistes, on reste frustré de ne pas savoir si la piété (ex-voto, conversions) et le rôle du clergé (au front et à l'arrière) ont contribué à un renouveau de la foi - qui expliquerait en partie la permanence de l'identité religieuse sous un régime athée.

5 Les récits soviétiques sur la guerre révèlent la barrière dressée pendant le conflit entre front - moral, franc et masculin - et arrière - immoral, veule et féminin. L'analyse de Petrone suggère aussi un rapport à l'héroïsme (masculin) fort ambigu. Un temps interdit d'expression au nom d'un pacifisme de vécu ou de conviction internationaliste, tenu dans l'ombre par les exploits des « héros » du Plan, l'héroïsme militaire gagne à nouveau droit de cité au milieu des années 1930, quand le discours s'oriente vers la mobilisation pour la guerre à venir. La littérature hésite sur la solidarité au front (peutelle transcender les classes comme en France ou doit-elle rester prolétarienne ?) et la désertion, un acte héroïque de résistance au tsarisme, mais aussi une trahison des camarades et de l'honneur national. Les littérateurs s'accordent en revanche sur l'émasculation des combattants, notamment invalides de guerre. Sans analyse de correspondances, de rapports psychiatriques ou de sources visuelles, cette affirmation paraît plaquée sur un vécu brossé à grands traits par Petrone. Les documents témoignent plutôt de l'infantilisation par une société qui refuse d'autant plus de les prendre en considération que les invalides ont formé les seules véritables associations d'anciens combattants de l'empire russe, et sont dépositaires à ce titre d'une mémoire corporative particulière.

Dans la littérature, la violence de guerre laisse son empreinte sur toutes les classes, elle ne révèle pas la lutte de classes. Le tabou de la sauvagerie du champ de bataille, longtemps faute rejetée sur les « autres» (ennemis ou surtout Cosaques), tombe : les combattants russes, présentés comme des tueurs malgré eux, apparaissent détruits par la violence perpétrée, privés d'humanité plutôt que "brutalisés». Ils tuent sans respecter aucun code de l'honneur, et maltraitent indistinctement civils étrangers et citoyens de l'empire. Le brouillage des identités gêne la définition patriotique autant 
que les contradictions politiques. "Être russe » peut avoir une connotation négative (les Cosaques), positive avec la solidarité de classe des ouvriers russes envers leurs camarades européens. L'« être allemand » est à la fois honni, atroce ; et digne de pitié, foyer de fraternité. La définition soviétique de l'identité russe subit ainsi sans la résoudre la tension entre patriotisme et cause internationaliste.

On retrouve donc ici l'essentiel des thèmes chers à la nouvelle histoire culturelle telle qu'on la pratique outre-Atlantique - excepté l'individuation (self), fait d'autant plus étonnant que certaines sources convoquées s'y prêtent très bien. Dans l'ensemble, ce plan apporte de nombreux éléments de compréhension, mais on peut se demander s'il convenait bien pour une réflexion axée sur la mémoire. Celle-ci reste trop souvent au niveau des discours imprimés et, sans même prétendre à inscrire ces représentations dans un substrat social commun aux années 1910 et 1920, leur élaboration n'est pas clairement dévoilée : quid des interactions entre auteurs, avec la censure, avec les lecteurs et les spectateurs? Quelles maisons d'édition publient ces textes, pourquoi à certaines époques, où se situe la frontière entre commande publique et "commande sociale»? Les ambiguiités du positionnement des auteurs, pointées par Petrone, qui gênent d'ailleurs constamment son analyse, tiennent-elles au double temps de collecte de l'information et de rédaction ou à des hésitations d'ordre politique?

Plus convaincant à nos yeux est le chapitre 6 « Arrested History » qui prend le temps de proposer plusieurs «études de cas mémoriels » et dont les résultats plaident pour une approche par types de mémoire, redonnant tout leur rôle aux acteurs de celle-ci. Le lecteur trouvera de précieuses informations sur le fameux cimetière fraternel de Moscou, la tentative de constituer une histoire militaire de la Grande Guerre, la réception populaire d'À l'Ouest rien de nouveau ou les publications accompagnant le vingtième anniversaire de l'entrée en guerre. Petrone estime que les luttes idéologiques entre institutions ou la discrétion forcée des héros de l'ancien régime ont refoulé la Grande Guerre dans les recoins de la mémoire publique. Mais elle insiste aussi avec raison sur la persistance d'une mémoire privée, à laquelle on fait parfois appel en fonction des besoins du moment. Réactivée au début de la "Grande Guerre patriotique ", la référence au premier conflit mondial se dissout ensuite sous l'effet des pertes traumatisantes et de l'euphorie de la victoire. Ce phénomène d'érosion n'est pas propre à l'Union soviétique; en revanche, l'absence de réactivation dans les années 1980 se distingue de l'expérience occidentale. Le dernier chapitre n'aborde guère cette problématique, sauf pour montrer que c'est l'alliance entre un nationalisme russe à la reconquête de son passé ante soviétique et l'Église orthodoxe qui fait finalement resurgir, à Moscou, une mémoire partielle et partiale de la Première Guerre mondiale.

9 L'essentiel du propos tire son essence de l'analyse historique et littéraire d'un certain nombre d'ouvrages clefs - mémoires, récits autobiographiques, nouvelles et romans et de quelques films. Ce choix s'explique certes par l'omniprésence des sources littéraires mais, s'il n'invalide pas l'essentiel des analyses, il souffre à notre avis de trois inconvénients. D'une part, les chapitres comportent de longs passages plus narratifs qu'explicatifs, faute de documentation sur les réalités sociales auxquelles font référence les textes et que partageaient alors auteurs et lecteurs. D'autre part, le traitement du cinéma apparaît non seulement de moindre ampleur, mais en partie fautif. Petrone se focalise sur les films toujours cités de Esfir' Šub (Padenie dinastii Romanovyh) ou de Boris Barnet (Okraina). Elle ignore d'autres fictions comme Oblomok imperii (F. Ermler, 1928) ou Ee put' (A. Strižak, 1929), et le documentaire de Jakuškin 
Mirovaja vojna (1929); et ne tient pas compte des contextes culturels, politiques et industriels fort différents présidant à ces réalisations. Il manque de fait un questionnement sur les liens entre littérature, théâtre et cinéma, et surtout une mise à plat de ce qu'on offre à la population en termes d'images fixes, de cérémonies du souvenir - bref, de relais collectifs et personnels à une mémoire qui n'est pas que culturelle et littéraire.

10 En ce sens, le titre de cet ouvrage recommandable constitue un raccourci trompeur. Il ne doit pas décourager l'enquête sur les (dis)continuités du souvenir de la Grande Guerre dans une nation qui s'apprête, pour la première fois depuis 1934, à la commémorer officiellement en 2014... sans doute pas dans la tonalité antimilitariste et parfois victimaire qui triomphe en Europe de l'Ouest. 